\title{
Affective dysregulation: a transdiagnostic research concept between ADHD, aggressive behavior conditions and borderline personality traits
}

\author{
Robert Waltereit ${ }^{1} \cdot$ Franziska Giller $^{1} \cdot$ Stefan Ehrlich $^{1} \cdot$ Veit Roessner $^{1}$
}

Published online: 11 November 2019

๑) Springer-Verlag GmbH Germany, part of Springer Nature 2019

In the last months, the German drama film "System Crasher" (German "Systemsprenger") by Nora Fingscheidt was one of the most controversial and broadly discussed motion pictures being released and presented at several film festivals. It is about the troubled 9-year-old girl, Benni, defying the child welfare system with one single goal: to be back at home with her mother. But her mother is scared of her own daughter. Benni is "out-of-control", showing frequent and severe temper outbursts comprising violent- and offending attacks to other people as well as full-throated screams and yelling. Nonetheless, this nimble-witted young bundle of energy has a different side: she is very needy and vulnerable. But, due to her inappropriate- and antisocial behavioral-tendencies, the child welfare system is unable to find a placement for her, and she is 'falling out of the system'. Fortunately, not only in Germany, the film has launched a broad public discussion about this group of children and adolescents at the intersection of child and adolescent psychiatry and child/ youth welfare system.

Aggressive symptoms are associated with a high rate of adverse childhood experiences, including severe traumatic bonding as one result of childhood maltreatment [1-3]. In turn, aggressive behaviors in children and adolescents can be linked to a substantially higher risk of developing mental disorders, including internalizing psychiatric disorders such as anxiety, and unipolar depressive disorders as well as autoaggressive behaviors such as suicide attempts [4, 5]. Next to mental disorders, antisocial behavior and delinquency are other possible consequences. Taken together, in children and adolescents aggression as well as associated symptoms such as impulsivity or irritability are not just disturbing behaviors,

Veit Roessner

veit.roessner@uniklinikum-dresden.de

1 Department of Child and Adolescent Psychiatry, Medical Faculty Carl Gustav Carus, TU Dresden, Fetscherstrasse 74, 01307 Dresden, Germany but serious markers of sometimes lifelong psychosocial burden including exclusion and stigmatization. The term "system crasher" points out the vast amount of psychosocial problems of children and adolescents with irritability, angry emotion, and impulsive aggression. But it has to be stated, that on average not the severity and impact of the core symptoms of the individual ICD-10 or DSM-5 diagnose(s), but rather the complexity of the individual behavioral problems hinder an appropriate care by appropriate support systems.

Although aggression, impulsivity, and irritability are dealt with in many research articles (for ECAP see Refs. [6-11]), a key problem is to assess these complex behaviors in terms of indication and choice of appropriate interventions as well as individual prognosis.

In this context, the terms affective dysregulation (AD) and irritability are largely used as synonyms. Most definitions characterize $\mathrm{AD}$ as excessive reactivity to negative emotional stimuli with an affective (anger) and a behavioral component (aggression) [12]. AD is related to the DSM-5 diagnosis of disruptive mood dysregulation disorder (DMDD). The term emotional dysregulation (ED) has similarly gained growing interest during the last decade, but is used and defined more broadly than $\mathrm{AD}$, causing some difficulties to distinguish it from other forms of dysfunction of emotion regulation or of emotion regulation in general. One plausible concept of ED and its mechanistic role in various disease conditions is that emotional instability and deficient emotional self-regulation cause inappropriate emotional responses [13].

During the last years, a variety of original contributions and review articles have been published for ED in the context of different child and adolescent psychiatric disorders such as attention-deficit hyperactivity disorder (ADHD), oppositionaldefiant disorder (ODD), conduct disorder (CD), DMDD and borderline personality disorder/traits in adolescence (BPD). But the ED concept can also be expanded to conditions such as obsessive-compulsive disorder (OCD), autism spectrum 
disorders (ASD) and to affective and psychotic disorders [14, 15]. These studies are offering a transdiagnostic and differential reflection of diverse disorders, featuring novel views on neurobiology and psychopathology and finally, a novel paradigm for pharmacotherapeutical and psychotherapeutical interventions [16-21].

The concept of AD appears, in contrast to ED, less established, but focuses on a more condensed construct of excessive reactivity to negative emotional stimuli with anger and disruptive aggressive behavior. In this more narrow definition of situationally externalizing behavior, AD differs from the description of general aggressive behavior as a complex mental function and from the broader concept of ED, which comprises both externalizing and internalizing behaviors. The similarly narrowly defined behavior non-suicidal self-injury (NSSI), by contrast, may be seen as an internalizing paradigm associated with ED. As both ED and the more narrowly defined NSSI were important and successful concepts to foster research in children and adolescents with ADHD and BPD, $\mathrm{AD}$ could have a similar perspective.

In this sense, the concept of $\mathrm{AD}$ has the advantage to be specific and, from a methodical point of view, a construct that can be easily investigated. As ED, AD is found in ADHD, ODD, CD, BPD, and DMDD. It can also be associated with OCD and ASD. Studying trajectories and long-term courses of $\mathrm{AD}$ could help to understand interrelations and transitions between these disease conditions. But a generally accepted instrument to assess $\mathrm{AD}$ is a major challenge on the way to further research. Currently, there is no specific rating scale available, while there are several established rating scales assessing ED [13]. The dysregulation profiles of the Childhood Behavior Checklist (CBCL-DP) and of the Strengths and Difficulties Questionnaire (SDQ-DP) represent currently practical approaches on the basis of available instruments [22,23].

More research is necessary and advisable to unravel and discover the opportunities of the AD construct. Looking specifically at the narrowly defined construct AD could improve the understanding of underlying neurobiological and psychopathological mechanisms. Finally, looking at the specific paradigm of $\mathrm{AD}$ as the primary outcome may improve and identify novel treatment strategies to help not only Benni and her mother but all children and families with these kind of problems.

Acknowledgements This work was supported by the research consortium on affective dysregulation, ADOPT, funded by the German Federal Ministry of Education and Research (FKZ 01GL1741[X])

\section{References}

1. Mumford EA, Taylor BG, Berg M et al (2019) The social anatomy of adverse childhood experiences and aggression in a representative sample of young adults in the US. Child Abuse Neglect 88:15-27. https://doi.org/10.1016/j.chiabu.2018.10.016

2. Lee V, Hoaken PNS (2007) Cognition, emotion, and neurobiological development: mediating the relation between maltreatment and aggression. Child Maltreat 12:281-298. https://doi. org/10.1177/1077559507303778

3. Dvir Y, Ford JD, Hill M, Frazier JA (2014) Childhood maltreatment, emotional dysregulation, and psychiatric comorbidities. Harv Rev Psychiatry 22:149-161. https://doi.org/10.1097/ HRP.0000000000000014

4. Jucksch V, Salbach-Andrae H, Lenz K et al (2011) Severe affective and behavioural dysregulation is associated with significant psychosocial adversity and impairment. J Child Psychol Psychiatry Allied Discip 52:686-695. https://doi.org/10.111 $1 /$ j.1469-7610.2010.02322.x

5. Rao U (2014) DSM-5: disruptive mood dysregulation disorder. Asian J Psychiatr. https://doi.org/10.1016/j.ajp.2014.03.002

6. Freitag CM, Konrad K, Stadler C et al (2018) Conduct disorder in adolescent females: current state of research and study design of the FemNAT-CD consortium. Eur Child Adolesc Psychiatry 27:1077-1093. https://doi.org/10.1007/s00787-018-1172-6

7. Schoorl J, van Rijn S, de Wied M et al (2017) Neurobiological stress responses predict aggression in boys with oppositional defiant disorder/conduct disorder: a 1-year follow-up intervention study. Eur Child Adolesc Psychiatry 26:805-813. https://doi. org/10.1007/s00787-017-0950-x

8. Bartels M, Hendriks A, Mauri M et al (2018) Childhood aggression and the co-occurrence of behavioural and emotional problems: results across ages 3-16 years from multiple raters in six cohorts in the EU-ACTION project. Eur Child Adolesc Psychiatry 27:1105-1121. https://doi.org/10.1007/s00787-018-1169-1

9. Sagar-Ouriaghli I, Milavic G, Barton R et al (2018) Comparing the DSM-5 construct of disruptive mood dysregulation disorder and ICD-10 mixed disorder of emotion and conduct in the UK Longitudinal Assessment of Manic Symptoms (UK-LAMS) Study. Eur Child Adolesc Psychiatry 27:1095-1104. https://doi. org/10.1007/s00787-018-1149-5

10. Katzmann J, Dopfner M, Gortz-Dorten A (2018) Child-based treatment of oppositional defiant disorder: mediating effects on parental depression, anxiety and stress. Eur Child Adolesc Psychiatry 27:1181-1192. https://doi.org/10.1007/s00787-018-1181-5

11. Noordermeer SDS, Luman M, Weeda WD et al (2017) Risk factors for comorbid oppositional defiant disorder in attention-deficit/ hyperactivity disorder. Eur Child Adolesc Psychiatry 26:11551164. https://doi.org/10.1007/s00787-017-0972-4

12. Leibenluft E, Stoddard J (2013) The developmental psychopathology of irritability. Dev Psychopathol 25:1473-1487. https://doi. org/10.1017/S0954579413000722

13. Faraone SV, Rostain AL, Blader J et al (2019) Practitioner review: emotional dysregulation in attention-deficit/hyperactivity disorder-implications for clinical recognition and intervention. $\mathbf{J}$ Child Psychol Psychiatry Allied Discip 60:133-150. https://doi. org/10.1111/jcpp.12899

14. Cai RY, Richdale AL, Uljarevic M et al (2018) Emotion regulation in autism spectrum disorder: where we are and where we need to go. Autism Res 11:962-978. https://doi.org/10.1002/aur.1968

15. Bayes A, Parker G, McClure G (2016) Emotional dysregulation in those with bipolar disorder, borderline personality disorder and their comorbid expression. J Affect Disord 204:103-111. https:// doi.org/10.1016/j.jad.2016.06.027

16. van Stralen J (2016) Emotional dysregulation in children with attention-deficit/hyperactivity disorder. ADHD Attent Deficit Hyperact Disord 8:175-187. https://doi.org/10.1007/s1240 2-016-0199-0

17. Lee CA, Milich R, Lorch EP et al (2018) Forming first impressions of children: the role of attention-deficit/hyperactivity 
disorder symptoms and emotion dysregulation. J Child Psychol Psychiatry Allied Discip 59:556-564. https://doi.org/10.1111/ jcpp. 12835

18. Pagliaccio D, Wiggins JL, Adleman NE et al (2017) Behavioral and neural sustained attention deficits in disruptive mood dysregulation disorder and attention-deficit/hyperactivity disorder. J Am Acad Child Adolesc Psychiatry 56:426-435. https://doi. org/10.1016/j.jaac.2017.02.008

19. Sobanski E, Banaschewski T, Asherson P et al (2010) Emotional lability in children and adolescents with attention deficit/hyperactivity disorder (ADHD): clinical correlates and familial prevalence. J Child Psychol Psychiatry Allied Discip 51:915-923. https ://doi.org/10.1111/j.1469-7610.2010.02217.x

20. Rufenacht E, Euler S, Prada P et al (2019) Emotion dysregulation in adults suffering from attention deficit hyperactivity disorder
(ADHD), a comparison with borderline personality disorder (BPD). Bord Personal Disord Emot Dysregul 6:11. https://doi. org/10.1186/s40479-019-0108-1

21. Moukhtarian TR, Mintah RS, Moran P, Asherson P (2018) Emotion dysregulation in attention-deficit/hyperactivity disorder and borderline personality disorder. Border Personal Disord Emot Dysregul 5:9. https://doi.org/10.1186/s40479-018-0086-8

22. Geeraerts SB, Deutz MHF, Dekovic M et al (2015) The child behavior checklist dysregulation profile in preschool children: a broad dysregulation syndrome. J Am Acad Child Adolesc Psychiatry 54:595-602.e2. https://doi.org/10.1016/j.jaac.2015.04.012

23. Holtmann M, Becker A, Banaschewski T et al (2011) Psychometric validity of the strengths and difficulties questionnairedysregulation profile. Psychopathology 44:53-59. https://doi. org/10.1159/000318164 